\title{
A review on design optimization approaches of coupled-structural acoustic systems
}

\author{
A. Emül, M. Ranjbar* \\ Ankara Ylldırım Beyazıt University, Department of Mechanical Engineering, Ankara, Turkey
}

\begin{abstract}
A survey on current design and optimization of coupled-structural acoustic systems (OCSAS) is presented. It reinforces different terminologies and methods in this field. General concepts are shortly defined, and literatures are reviewed for further investigation. Although surveys of optimization for coupled-structural acoustic systems are common, they are frequently incomplete in terms of extensive scope general applicability to engineering design. For instance, many surveys only target determined applications while others only mention the critical literature in the field. Outcomes are drawn that represent often-neglected ideas and applicability to engineering problems. It has been found that no single approach is outstanding. On the contrary, the selection of a determined method depends on the type of knowledge that is supplied in the problem, the user's preferences, the solution necessaries, etc. Also, new emerging research fields are introduced.
\end{abstract}

\section{Keywords}

Optimization, Design, Coupled-structural acoustic systems, Vibration, Application, Review

Received: 28 May 2018; Accepted: 30 June 2018

ISSN: 2630-5763 (online) C 2018 Golden Light Publishing® All rights reserved.

\section{Introduction}

The coupling term has a great emphasis on engineering as well as many different areas. It is a term that serves to connect the ends of adjacent parts or objects [1]. In mechanical engineering, coupling provides to connect of two parts of a machine or a system. For electronic, coupling is the connection of two or more circuits together. The devices that perform the joining phenomena are called couplers [2]. In telecommunications, an acoustic coupler is an interface device for coupling electrical signals by acoustical means. Acoustic coupling refers to acoustic impedance or the degree of transmission of sound across some acoustic barrier [3].
System is the sense of "a functionally associated group of components forming or described to collective entity" [4]. That definition uses "component" as a generic term that embodies "element" or "part", which connotes simplicity, as well as "subsystem" which connotes complexity. Felippa et al. [5] had restricted to attention to mechanical systems, and especially that importance in aerospace and mechanical engineering.

A coupled system (CS) is a system in which physical or computational heterogeneous mechanical components interact dynamically. A coupled system is characterized as two or more fields that appear in the first level decomposition [4]. Coupled systems alter between a lot of operating modes where each mode is administered

\footnotetext{
* Corresponding author

E-mail: mranjbar@ybu.edu.tr
} 
by its own characteristic dynamical laws [6]. The scholarly literature of coupled systems with coupled disparate qualification fields covers almost all branches of science [7], for instance, biological sciences, chemistry and chemical engineering, astronomy, earth and planetary sciences, computer science, engineering, energy and technology, environmental sciences, life sciences, materials science, mathematics, medicine, etc. The interest in examining unified systems as a new qualitative system has been multiplying exponentially over the last few years due to theoretical difficulties that have arisen in the study of such systems [7]. Felippa et al. [4] performed a study on the use of partitioned analysis procedure for the analysis of coupled dynamical systems. In that study, they focused on computational simulation of systems in which structure is a major component.

The analysis of structural-acoustic systems (SAC) is an ongoing and evolving hotspot of active research fields. There are many practical problems are characterized by an internal structural-acoustic system, which contains an air-filled cavity and some flexible boundaries. Since the introduction of the energy formulation by Gladwell et al. [8], the structural-acoustic systems have been extensively enquired. Various numerical methods and techniques such as the finite element method (FEM) [9], the boundary element method (BEM) $[10,11]$, the statistical energy analysis (SEA) [12] and the energy finite element method (EFEM) [13] have been used in the response analysis of structural-acoustic systems. Many real-world structural-acoustic systems are subject to indiscriminate excitations, and thus random response analyses of such systems are necessary [14]. For instance, in automotive design, lots of efforts have been made in reduction interior wind noise rising from the airflow around the vehicle [15]. The interaction between a flexible vibrating structure and a closed space is of great interest to researchers in different fields, such as vehicle compartments, aircraft and ship cabins [16]. Peretti et al. [17] gave a review to investigate the vibroacoustic behavior of such systems, such as modal interaction of coupled structural-acoustic systems. Some experimental studies had indicated that coupling between the structure and the acoustic field can be significant. Typical examples of coupled structural-acoustic systems are automobile compartments or aircraft cabins where the interior noise couples with part or all the body or fuselage structure [18]. In aerospace applications, the boundary layer of the external airflow results in an indecisive pressure on the fuselage and the noise is thus transmitted into the internal areas $[19,20]$. For road and aerospace vehicles noise, vibration and harshness are very important issues. There are many factors that affect this condition. One of the reasons for this situation is coupling. The coupling between a structure and an internal or external acoustic medium cause of these condition. The magnitude of the structural noise strongly influences the habitability, comfort, and perceived quality of these vehicles. [21]. Because of this, particularly for aerospace vehicles an elevated level of vibration and noise can cause structural fatigue damage. In many cases, the airplanes or other aerospace vehicles must meet strict vibroacoustic standards [22].

The coupled structural-acoustic system can be a reasonable issue in many engineering occasions, which are consisted of an acoustic space and a flexible wall surface. Studies on structural-acoustic coupling have been comprehensively fulfilled [23]. Dowell et al. [24] had tried to analyze the effect of a cavity on panel vibration. Lyon [25], had studied the noise reduction of a rectangular enclosure with one flexible wall. Pretlove [26,27] had studied the effect of a closed cavity on the vibrations of a bounding flexible panel. Former studies had aimed at improving the understanding of sound transmission through panels [28]. Coupled acoustic-structural problems are particularly significant issues in the engineering fields, where the vibrating exterior structures induce interior noise, such as aerospace, automobile, and marine [29]. Numerical methods have been used comprehensively to forecast sound level of the acoustic-structural systems [30-32]. These methods set sight on mainly on calculating the deterministic frequency response of the coupled acoustic- 
structural systems subjected to the deterministic excitations. After all, the coupled acousticstructural systems depending on stochastic excitations are also frequently existent in the engineering applications [33-35]. Over the past three decades, the studies about such random analysis methodologies have received special attention [29]. Using the distributed piezoelectric actuators, the inner noise in a three-dimensional car cabin was minimized. In that study, two issues about the interior noise active control were discussed. The first of these were the modeling technique. Modal synthesis method had been used to establish the governing equations of motion of the fully coupled acoustics-structure-piezoelectric patch system using modal frequencies, damping and mode shapes of a structural and an acoustical system which appear in the frequency range of interest. The other issue was the optimization of piezo actuator's positions. A new response surface methodology MPOD (most probable optimal design) based on holographic neural network, proposed by the authors had been applied to solve the global optimal positions of piezoelectric patches [36]. Optimization techniques have so far been used for structural-acoustic purposes. However, Maburg et al. [37] have done a study that describes a general approach of utilizing optimization procedures in vehicle noise, vibration and harshness problems. First, they started with a review of structural-acoustic optimization. Then, the noise transfer function including structural harmonic analysis, acoustic influence coefficients and their coupling was described. They have followed by some remarks on the optimization process, discussing objective functions, useful design parameters and sensitivity analysis. Two examples including a hat-shelf and a floor structure has been presented in the application section.

In this paper, a brief review will be done to learn the background of structural acoustic design problem. Various approaches of design optimization of structures with respect to their vibroacoustic and acoustical radiation properties will be presented. At the end, some promising research areas which are still on demand in the field will be presented.

\section{Survey of optimization on coupled-structural acoustic systems}

\subsection{Methods of optimization for coupled- structural acoustic systems}

Aircraft noise has become a significant factor that endangers public health and acoustic navigability. Decrease the noise and optimizing the structuralacoustic system in an influential way is of great significance [38]. Because of the uncertainties existing in the structural or acoustic parameters, traditional deterministic optimization may be impossible when the parameters are subject to fluctuations. When the structural or acoustic parameters have an uncertainty, the design sketch acquired from the deterministic optimization may be beyond the scope of the method. In structuralacoustic coupled systems, some ambiguous factors are inevitably in nearly all structures due to the randomness of loading conditions, material properties and simulation modelling [39]. Therefore, they had to develop an optimization method that could consider the uncertainties in the related parameters. To complete successfully this, they proposed a robust optimization method of structural-acoustic coupled systems with random parameters based on the traditional optimization method [38]. Two methods of robust optimization for structural-acoustic systems are introduced to comprise the goal function robustness and the constraint condition robustness. The multiobjective optimization problem was transformed into a single objective problem using a weight factor.

The results of the two numerical examples illustrate the efficiency of the proposed robust optimization method [38]. Robust optimization is a practicable method for being interested uncertainties and it has been widely used in structural design optimization. Taguchi [40] originally recommended a robust design concept to conduct the uncertain optimization problem. Kang et al. [41] studied the nonlinear structural robust 
design problem using the perturbation-based stochastic finite element analysis incorporating structural optimization techniques. Chen [42] introduced the basic concept, mathematical specification and implementation process of the six sigma-based robust design optimizations. Xiao et al. [43] examined dynamic problems by optimizing the integrity and constraint conditions of the objective function. Zhang et al. [44] presented a robust optimization design method for the advanced grid composite cylindrical crust with initial-failure. Wang et al. [45] negotiated the trustworthiness, optimum design, trustworthinessbased optimization and robust optimization for laminated composites.

Some scientist has studied the structuralacoustic optimization problem. Structural-acoustic optimization frequently takes the minimum structural weight as an objective function and the acoustic pressure at the design field points and either the total acoustic radiation pressure of the structures as or the minimum acoustic intervention as an objective while the structural weight as the constraint condition [22]. Zhang et al. [46, 47] executed the optimal geometric design of the structures to minimize the acoustic pressure at positions and frequencies of interest using the feasible direction method and the acoustic interference characteristics were utilized-based on the 3-D FEM model with the direct method. The aim of work by Wang et al. [38] was to apply the robust design method to structural-acoustic systems to appraise the situation the uncertainties in the structural or acoustic parameters. The main goal of them the robust optimization was to decrease the sensitivity of the random variables and to develop the structural and acoustic performance. In that study, two robust optimization methods of structural-acoustic coupled systems were established. Deterministic optimization and robust optimization were compared, and the results demonstrate the advantage of the robust optimization [38]. Dammak et al. [48] had studied an analytical formulation and numerical implementations of the response of the coupled structure-acoustic system were implemented. The acoustic pressures inside the cavity as well as the plate displacement were analyzed. That study is combined with a probabilistic analysis to account for variability of different parameters, considered as random variables, which are material properties. A reliability based design optimization (RBDO) using the generalized polynomial chaos ( $\mathrm{gPC}$ ) is addressed. To reduce the computational cost of the classical approaches of RBDO problem, the optimum safety factor (OSF) method coupled with the $\mathrm{gPC}$ procedure is applied to the coupled acoustic-structure systems.

\subsection{Reduction of noise and vibration in powertrain systems}

Vibration, noise and harshness are one of the primary features in a passenger car [49]. One of the key sub-systems be in for VNH behavior of a car is the Powertrain Mounting System (PMS). The difficulty in designing a PMS is how to designate the stiffness and the damping of the mounts and how to appropriately establish them in a vehicle to control the motion of the powertrain, to decrease the vibration of the powertrain beneath excitation of ground and to seal off the vibration of engine transmitted to car body or subframe [50].

The recipients of a passenger car perceive noise and vibration usually at the cabin where the vibrations at seat track or steering wheel and the noise at ear side. How to constitute the mount locations and stiffness and damping to meet the necessity of vibration and noise at the cabin is that a challenging task for the PMS design engineers [49]. Singh et al. [51, 52] suggests an analytical method of decoupling automotive powertrain dependently the concept of torque roll axis if the base is rigid or compatible. Ashrafiuon et al. [53] presented dynamic equations for a PMS consideration of the flexibility of the ground and fulfill optimization of an aircraft engine mount by minimizing the transmitted force to the base. The flexibility of the chassis made by mode information of chassis or sub-frame with FEA or experimental mode tests. Experimental and numerical analysis were used to optimize the vibration and noise of the cabin [54,55]. Shangguan et al. [49] presented the 
design target for a PMS regarding vibration and noise limitations of vehicle level contributed form mounts is defined. Design rigidity and calculation methods are proposed to determine the mounting rigidity and damping, which are based on vehiclelevel vibration and noise reduction from PMS [49]. Gear motion leads to gear-rattling noise and gearclattering noise, and a low noise level is necessary for high comfort in the automotive design. Consequently, decrease gear-rattling noise and gear-clattering noise in the automotive transmission is necessity to augment the comfort level in car design [56]. The main transmission noises are rolling contact noises of gear pairs that under load, which can be defined as whining noises. Tooth toughness changing with the intertwine position causes the whining noises. A second kind of noise is gear-rattle noise, which may consist of with automotive transmissions if uncharged gear wheels are excited by torsional vibration [56]. Optimization of the macro-geometry with a high contact ratio for the toothed gears results in a reduction in noise levels. Optimization of microgeometry for gear teeth with profile corrections usually results in lower transmission noise [57]. Bozca [56] studied to reduce the gear-rattle noise of the five-speed manual gearbox, which is used in automotive transmissions, by minimizing the transmission error. Reducing gear-rattling noise in an automotive transmission gearbox, it is probable to attain a comfortable car design that is susceptible to the environment and humans.

\subsection{Reducing noise of internal combustion engine}

Internal combustion engine noise has drawn attention since it is associated with the passengers' and pedestrians' discomfort, as a fact that has been acknowledged by the manufacturers and the legislation in many countries [58]. There are three primary sources of noise generation in a diesel engine such that gas-flow, mechanical processes, and combustion [59-61]. Jung et al. [62] investigated the source of the combustion noise of diesel engines. In the refinement of exhaust emission and combustion noise, it must be optimizing the injection parameters at the cell where engine noise cannot be measured to figure out this problem, it is essential to identify a method for progressive combustion noise through incylinder pressure measurement. Gazon et al. [63] studied the outcome about the impact of engine coolant temperature and injection timings on the combustion operate and on the combustion noise at idle condition They used a modern direct injection Diesel engine equipped with a common-rail injection system and piezoelectric injectors. They found that the combustion noise is precision to both the coolant temperature and the dwell time among the pilot and the main injection [63]. The combustion noise reaches its maximum level when the combustion of the pilot injection occurs at Top Dead Centre (TDC) [63]. Optimization of combustion noises and exhaust gas emissions is often carried out up to the part load and the low revolution middle speed. The calibration required to generally meet the desired exhaust gas emission level may cause an increase in the combustion noise on the part load.

\subsection{Optimization of muffler for decreasing exhaust gas noise level}

A muffler is a significant part of an engine system used in the exhaust system to decrease the exhaust gas noise level. If vehicles did not have a muffler there would be an irresistible amount of engine exhaust noise in our surroundings [64]. Yao et al. [65] had done work on optimal design and the test on a reactive muffler of a vibratory roller based on the CFD and experimental study. The performance of the muffler influences the level of the machine's radiated noise and influence also the power loss of the engine. Many scholars studied the exhaust muffler of automobiles or internal combustion engine and it was pointed that commercial automotive mufflers are often complex and difficult to be analyzed with pre-established transfer matrices [66]. With help of noise measure and simulation analysis working, some new simulation approximation was applied to appraise the transient acoustic features of exhaust muffler [67] and the transmission loss of the muffler [68]. 
In a series of publications by Ranjbar et al. [6995], various researches on vibration design of multibody systems, vibroacoustic optimization of shell and sandwich panels, and acoustic design and optimization exhaust systems were presented. The main concept was to optimize the system with respect to its noise radiation characteristics. They showed that multidisciplinary engineering design optimization of structures is an emerging research field.

\subsection{Noise, harshness and vibration optimization of hybrid and electric vehicles}

Vehicles bedecked with internal combustion engine (ICE) have been in presences for over a hundred years. Despite ICE vehicles (ICEVs) are being improved by modern automotive electronics technology, they need a major change to considerably develop the fuel economy, decrease the emissions, noise and vibrations [96]. Electric vehicles (EVs) and hybrid EVs (HEVs) have been described to be the most practicable solutions to substantially solve the problems in association with ICEVs [97]. At low speeds, an electric vehicle is very quiet and does not generate harmful emissions when compared to a gasoline or diesel-powered vehicle [98-100]. In the past few years, utilization of Hybrid Electric Vehicles (HEVs) has considerably escalated due to the boosting damage in the global environment [101]. When promotion modern technologies, the manufacturers are facing rigorous customer expectancies regarding sound and comfort quality, dynamics and drivability of the vehicle. Furthermore, HEVs are well known as straight and silent drives, but owing to rising in complexity, extra vibro-acoustic effects may concern the design of vehicle behavior. With the absence of an Internal Combustion Engine (ICE) masking properties, noise and vibration $(\mathrm{N} \& \mathrm{~V})$ effects, which are of low significance in traditional drivelines, may become important matters in a HEV. To accomplish these issues, significant amount of research and development has been implemented in the field of modeling, simulation and control of hybrid powertrain systems [102]. Parmar et al. [103] presented a detailed analysis of the starting behavior of a micro/mild hybrid vehicle with Crankshaft Starter Generator (CSG). Sound quality of electric traction motors replacing the ICE in hybrid/electric vehicles is in detail unexplored area. The signature sound from automotive emotors, usually permanent magnet synchronous motors (PMSM), is fully dissimilar from ICEs. Besides being in general quieter, they are described by multiple high-frequency tonal ingredient originating from harmonics of the electromagnetic force waves representation on the stator housing. High frequency tones visible in a broad band mix of sound has been found to be sense as disturbing in many varied situations. Parizet et al. [104] showed that perceived unpleasantness increases with increasing level and frequency for pure tones ranging from 150 to $2900 \mathrm{~Hz}$ appearing in on an equal basis masking noise. For automotive practices, Lennström et al. [101] found that an increase in levels of individual high frequency ingredient $(>1 \mathrm{kHz})$ resulted in higher rating in perceived annoyance, sharpness, aggressiveness and powerfulness and also lowered the impression of entire sound quality satisfaction [105]. That paper presented a more elaborate study on the relation between practical measures of e-motor tones appearing in a mix of random noise from tires and wind and the perceived annoyance.

\section{Conclusions}

A brief review on the design and optimization of coupled-structural acoustic systems was explained. Their engineering applications were clarified briefly. Various applications were explained. The noticeable issues can be summarized as:

- Design optimization methods have gained wide attention in literatures.

- Uncertainties in structural-acoustic coupled systems are inevitable.

- $\quad$ The robust design methods were used to appraise the uncertainties in the structural or acoustic parameters.

- The application of metamaterials with negative Poisson ratios in vibration and vibroacoustic designs will be an emerging field. 
- Design of novel sandwich panels with Auxetics cores is an ongoing research, especially for aerospace applications where high frequency ranges are important.

- The optimum design of large-scaled mufflers and exhaust systems for industrial applications will be more on demand.

\section{References}

[1] URL1: Webster M. Definition of coupling. https://www.merriamwebster.com/dictionary/coupling. 12122017.

[2] URL2: The Free Dictionary, Flarex. https://encyclopedia2.thefreedictionary.com/aco ustic+coupler. 12122017.

[3] URL3: Glottopedia. http://www.glottopedia.org/ index.php/Acoustic_coupling. 12122017.

[4] Felippa CA, Park KC, Farhad C (2001) Partitioned analysis of coupled mechanical systems. Computer method in Applied Mechanical Engineering 190: 3247-3270.

[5] Hedrih K (2008) Dynamics of coupled systems. Nonlinear Analysis: Hybrid Systems 2: 310-334.

[6] Hedrih K (2006) Energy analysis in a nonlinear hybrid system containing linear and nonlinear subsystems coupled by hereditary element. Nonlinear Analysis: Hybrid Systems 51: 127140.

[7] Gladwell G, Zimmerman G (1996) On energy and complementary energy formulations of acoustic and structural vibration problems. Journal of Sound and Vibration 3(3): 233-241.

[8] Nefske DJ, Wolf JJA (1982) Structural-acoustic finite element analysis of the automobile passenger compartment: a review of current practice. Journal of Sound and Vibration 80(2): 247-266.

[9] Goswami P, Rizzo F, Shippy D (1988) Acoustic scattering by elastic solids using the boundary element method. Review of Progress in Quantitative NDE 7: 95-102.

[10] Li S (2005) An efficient technique for multifrequency acoustic analysis by boundary element method. Journal of Sound and Vibration 283: 971-980.

[11] Renji K, Nair P, Narayanan S (2006) Acoustic response behavior of panels mounted with equipment and its prediction using statistical energy analysis. Journal of Sound and Vibration 289: 851-870

[12] Dong J, Choi K, Wang A (2005) Parametric design sensitivity analysis of high frequency structural-acoustic problems using energy finite element method. International Journal of Numerical Methods in Engineering 62: 83-121.

[13] Zhao G, Chen G, Kang Z (2012) An iterative algorithm for analysis of coupled structuralacoustic systems subject to random excitations. Acta Mechanica Sinica 28(2): 458-467.

[14] Keji S, Toyoki S (1995) Research on aerodynamic noise around automobiles. Society of Automotive Engineers of Japan Review 16(2): 157-165.

[15] Dammak K, Koubaa S, Walha L, Haddar M, El Hami K (2017) Reliability based design optimization of coupled acoustic-structure system using generalized polynomial chaos. International Journal of Mechanical Sciences 134: 75-84.

[16] Holkamp J, Gordon R (2010) Coupling acoustic modal models to nonlinear structural reducedorder models. U.S. Air Force Research Laboratory.

[17] Zhu Y, Qui J, Du H, Tani J (2003) Simultaneous structural-control optimization of a coupled structural-acoustic enclosure. Journal of Intelligent Material Systems and Structures 15(5): 287-296.

[18] Mathur G (1996) Sound transmission through stiffened aircraft structures. In: Proceeding of NOISECON96., Inst. of Noise Control Engineering, Saddle River, NJ, USA.

[19] Mixon J, Wilbey J (1995) Chapter 16. Interior noise. In: Hubbard Aeroacoustics of Flight Vehicles, Noise Control, Acoustical Society of America.

[20] Puri R, Morry D, Bell A, Durodola J, Rudnyi E, Korvink J (2009) Reduced order fully coupled structural-acoustic analysis via implicit moment matching. Applied Mathematical Modelling 33: 4097-4119.

[21] Wang X, Li Y, Ma Z, Fan W, Wang L, Xu M (2017) Robust optimization of structuralacoustic coupled system with random parameters. Aerospace Science and Technology 60: 48-57.

[22] Shi S, Su Z, Jin G, Liu Z (2018) Vibro-acoustic modeling and analysis of a coupled acoustic system comprising a partially opened cavity 
coupled with a flexible plate. Mechanical Systems and Signal Processing 98: 324-343.

[23] Dowell E, Voss H (1963) The effect of a cavity on panel vibration AIAA Journal, 1(2): 476-477.

[24] Lyon R (2005) Noise reduction of rectangular enclosures with one flexible wall. The Journal of the Acoustical Society of America 35: 17911797.

[25] Pretlove A (1965) Free vibrations of a rectangular panel backed by a closed rectangular cavity by a closed rectangular cavity. Journal of Sound and Vibration 2(3): 197-209.

[26] Naryannan S, Shanbhag R (1981) Acoustoelasticity of a damped sandwich panel backed by a cavity. Journal of Sound and Vibration 78(4): 453-473.

[27] Guy D, Bhattacharya M (1973) The transmission of sound through a cavity backed finite plate. Journal of Sound and Vibration 27(2): 207-216.

[28] Shang L, Zhao G, Zhai J (2017) Topology optimization for coupled acoustic-structural systems under random excitation. Structural and Multidisciplinary Optimization 56(4): 809-822.

[29] Craggs A (1971) The transient response of a coupled plate-acoustic system using plate and acoustic finite elements. Journal of Sound and Vibration 15(4): 509-528.

[30] Gan R, Sun Q, Feng B, Wood M (2006) Acoustic-structural coupled finite element analysis for sound transmission in human earpressure distributions. Medical Engineering \& Physics 28(5): 395-404.

[31] Nefske DJ, Wolf JA, Howell LJ (1982) Structural-acoustic finite element analysis of the automobile passenger compartment: A review of current practice. Journal of Sound and Vibration 80(2): 247-266.

[32] Davies H (1971) Low frequency random excitation of water-loaded rectangular plates. Journal of Sound and Vibration 15(1): 107-126.

[33] Sumitani K, Shinhora T (1995) Research on aerodynamic noise around automobiles JSAE Review, 16(2): 157-164.

[34] Hubbard H. Interior noise. Aeroacoustics of Flight Vehicles: Theory and Practice 2: 271-355, 1991.

[35] Shi Q, Hagiwara I (1999) Optimization of piezoelectric actuator for active interior noise control. Optimization of structural and mechanical systems, proceedings, Tokyo.
[36] Marburg S, Hardke HJ. An optimization technique in structural-acoustic design of sedan body panels. IUTAM Symposium on Designing for Quietness: Proceedings, 2002, Bangalore, India.

[37] Wang X, Li Y, Ma Z, Fan W, Wang L, Xu M (2017) Robust optimization of structuralacoustic coupled system with random parameters. Aerospace Science and Technology 60: 48-57.

[38] Tsui K (1992) An overview of Taguchi method and newly developed statistical methods for robust design. IIE Transactions 24(5): 44-57.

[39] Kang Z, Chen G (2006) Structural robust design based on perturbation stochastic finite element method. Chinese Journal of Computational Mechanics 23(2): 129-135.

[40] Chen S (2015) The concept of six sigma-based robust design optimization, Equipment Design and Maintenance 19(4): 87-89.

[41] Xiao F, Jian K (2007) Application of robust optimal design in structural dynamics. Gongcheng Lixue/Engineering Mechanics 24(1): 62-65

[42] Zang, Z, Chen H, Bai R (2006) Robust optimization of advanced grid composite cylindrical shell considering initial imperfect effect. Acta Mechanica Solida Sinica 27: 58-63.

[43] Wang X, Wei J (2005) Advances in the reliability-based optimization study for laminated composites. Advanced in Applied Mechanics 35: 541-547.

[44] Zhang J, Wang Z, Xie S, Zhang W (2005) Acoustic design optimization for coupled acoustic-structural systems. Journal of Vibration Engineering 18(4): 519-523.

[45] Dammak K, El Hami A, Kouba S, Walha L, Haddar M (2017) Reliability based design optimization of coupled acoustic-structure system using generalized polynomial chaos. International Journal of Mechanical Sciences 134: 75-84.

[46] Shangguan W, Liu X, Lve P, Rakheja S (2016) Design method of automotive powertrain mounting system based on vibration and noise limitations of vehicle level. Mechanical Systems and Signal Processing 1: 677-695.

[47] Shangguan W (2009) Engine mounts and powertrain mounting systems: a review. International Journal of Vehicle Design 49(4): 237-258 
[48] Jeong T, Singh R (1999) Analytical methods of decoupling the automotive engine torque roll axis. Journal of Sound and vibration 234(1): 85114.

[49] Jae Y, Singh R (2008) Effect of engine mount damping on the torque roll axis decoupling. Journal of Sound and Vibration 333: 841-857.

[50] Hashem A (1993) Design optimization of aircraft engine-mount systems. Journal of Vibration and Acoustics 115(4): 463-467.

[51] Madjlesi R, Khajepour A, İsmail F, Mihalic J, Rice B (2003) Advance noise path analysis: A robust engine mount optimization tool. SAE Technical Paper Series https://doi.org/10.4271/ 2003-01-3117.

[52] Eisele G, Wolff K, Alt N (2005) Application of Vehicle Interior Noise Simulation (VINS) for NVH Analysis of a Passenger Car. Technical Paper Series 01-2514.

[53] Bozca M (2018) Transmission error model-based optimization of the geometric design parameters of an automotive transmission gearbox to reduce gear-rattle noise. Applied Acoustics 130: $247-$ 259.

[54] Bellomo P, Cricenti F, Vito N, Lang C, Minervini D (2000) Innovative vehicle powertrain systems engineering: beating the noisy offenders in vehicle transmissions. Detroid, Michigan, USA.

[55] Giakoumis E, Dimaratos A, Rakopoulos C (2011) Experimental study of combustion noise radiation during transient turbocharged diesel engine operation. Energy 36(8): 4983-4985.

[56] Challen B, Baranescu R (1984) Diesel engine reference book. London: British Library Cataloguing in Publication Data.

[57] Taylor C. Combustion, Fuels, Materials, Design. Cambridge: MA: MIT Press, 1985.

[58] Li W, Gu F, Ball A (2001) A Study of noise from diesel engines using the independent component analysis. Mechanical Systems and Signal Processing 15(6): 1165-1184.

[59] Jung I, Jin J, So H, Nam C, Won K (2013) An advanced method for developing combustion noise through the analysis of Diesel combustion. SAE International Journal of Engines 6(2): 13791385.

[60] Gazon M, Blaisot J, De L'stoille N (2005) Effect of coolant temperature on combustion and combustion noise fluctuations in a Diesel engine at idle conditions. Control Engineering Practice 123(5): 197-211.
[61] Mundhe V, Deore E (2015) Design and optimization of perforated muffler in an automobile exhaust system. International Journal of Applied Research 1(8): 390-395.

[62] Yao Y, Wei S, Zhao J, Chen S (2013) Experiment and CFD analysis of reactive muffler. Research Journal of Applied Sciences Engineering and Technology 6(17): 3282-3288.

[63] Panigrahi S, Munjal M (2007) A generalized scheme for analysis of multifarious commercially used mufflers. Applied Acoustics, 68(6): 660-681.

[64] Yasuda T, Wu C, Nakagawa N, Nagamura K (2010) Predictions and experimental studies of the tail pipe noise of an automotive muffler using a one-dimensional CFD model. Applied Acoustics 71(8): 701-707.

[65] Wu C, Wang X, Tang H (2008) Transmission loss prediction on a single-inlet/double-outlet cylindrical expansion-chamber muffler by using the modal meshing approach. Applied Acoustics 69(2): 173-178.

[66] Lee J, Jang G (2012) Topology design of reactive mufflers for enhancing their acoustic attenuation performance and flow characteristics simultaneously. Numerical methods in engineering 91(5): 552-570.

[67] Barbieri R, Barbieri N (2006) Finite element acoustic simulation based shape optimization of a muffler. Applied Acoustics 67(4): 346-357.

[68] Kakade S, Sayyad F (2017) Optimization of exhaust silencer for weight and size by using noise simulation for acoustic performance. International Journal of Innovative Research in Science and Engineering 3(4): 49-60.

[69] Mazloomi S, Ranjbar M, Boldrin L, Scarpa F, Patsias S, Ozada N (2018) Vibroacoustics of 2D gradient auxetic hexagonal honeycomb sandwich panels. Composite Structures. 187: 593-603.

[70] Ranjbar M, Boldrin L, Scarpa F, Niels S, Patsias S (2016) Vibroacoustic optimization of antitetrachiral and auxetic hexagonal sandwich panels with gradient geometry. Smart Materials and Structures 25: 054012.

[71] Hussain G, Ranjbar M, Hassanzadeh S (2015) Trade-off among mechanical properties and energy consumption in multi-pass friction stir processing of al 7075-t651 alloy employing hybrid approach of artificial neural network and genetic algorithm. Proceedings of the Institution 
of Mechanical Engineers Part B: Journal of Engineering Manufacture 231(1): 129-139.

[72] Ranjbar M, Marburg S, Hardtke HJ (2012) Structural-acoustic optimization of a rectangular plate: a tabu search approach. Journal of Finite Elements in Analysis and Design 50: 142-146.

[73] Ranjbar M, Hardtke HJ, Fritze D, Marburg S (2010) Finding the best design within limited time: a comparative case study on methods for optimization in structural acoustics. Journal of Computational Acoustics 18(2): 149-164.

[74] Ranjbar M, Marburg S, Hardtke HJ (2012) A New hybrid design of experiments approach for optimization in structural acoustics applications. Applied Mechanics and Materials, 110(116): 5015-5020.

[75] Ranjbar M, Tadayon A (2017) Vibration analysis of multi degree of freedom self-excited systems. Journal of Robotic and Mechatronic Systems 2(1): 1-8.

[76] Ranjbar M, Nahid M, Renawi A, Sadeqi Z (2017) Development of an educational noise reduction measurement test bench. Journal of Robotic and Mechatronic Systems 2(1): 27-32.

[77] Ranjbar M, Alinaghi M (2016) Effect of liner layer properties on noise transmission loss in absorptive mufflers. Mathematical Modelling and Applications 1(2): 46-54.

[78] Ranjbar M, Gharooni Saffar M (2016) A sensitivity analysis on application of artificial neural networks in structural acoustics. Journal of Robotic and Mechatronic Systems 1(2): 23-26.

[79] Ranjbar M, Kemani M (2016) A comparative study on design optimization of mufflers by genetic algorithm and random search method. Journal of Robotic and Mechatronic Systems 1(2): 7-12.

[80] Ranjbar M, Marburg S (2013) Fast vibroacoustic optimization of mechanical structures using artificial neural networks. International Journal of Mechanical Engineering and Applications 1(3): 64-68.

[81] Ranjbar M, Marburg S, Hardtke HJ (2013) Vibroacoustic optimization of mechanical structures: a controlled random search approach. Advanced Material Research 622(623): 158-161.

[82] Ranjbar M, Marburg S (2012) Vibroacoustical optimization of mechanical structures using geometry modification concept and genetic algorithm method. Journal of Mechanical
Engineering, Tarbiat Modares University, 12(2): 134-143.

[83] Ranjbar, M. A comparative study on optimization in structural acoustics. PhD. Thesis, Technische Universität Dresden, Germany, 2011.

[84] Ranjbar M (2007) Development of hybrid robust optimization strategies for structural-acoustic applications. In the annual report of the PanEuropean Research Infrastructure on High Performance Computing (HPC-Europa), University of Bologna, Italy.

[85] Ranjbar M, Khadem SE (2001) Development of vibration analysis using Gabor transformation for machinery fault diagnosis. Journal of Amirkabir University 12(48), (in Persian).

[86] Ranjbar M, Keskin O, Demirtaş S, Karakoca Y $\mathrm{E}$, Arslan H. Designing and manufacturing of a modal analysis test bench-part one: harmonic shaker development. International Symposium on Multidisciplinary Studies and Innovative Technologies Gaziosmanpaşa University Tokat / Turkey, 2017.

[87] Ranjbar M, Dalkılıç B, Çalık E, Arslan MC, Arslan H. On muffler design for transmitted noise reduction. International Symposium on Multidisciplinary Studies and Innovative Technologies Gaziosmanpaşa University Tokat/Turkey, 2017.

[88] Mazloomi S, Ranjbar M, Sarpa F, Ozada N. Vibroacoustic Optimization of 2-dimensional gradient auxetics sandwich panels. Medyna 2017: 2nd Euro-Mediterranean Conference on Structural Dynamics and Vibroacoustics, 2017 Sevilla, Spain.

[89] Ranjbar M, Orhan S. Self-excited vibration of the three-degrees of freedom system. The 25th Annual International Conference on Mechanical Engineering (ISME), 2017, Tehran, Iran.

[90] Ranjbar M, Kermani M. Muffler design by noise transmission loss maximization on narrow band frequency range. The 7 th Automotive Technologies Congress (OTEKON 2014), 26-27 May 2014, Bursa, Turkey.

[91] Ranjbar M, Kermani M. On Maximization of noise transmission loss in mufflers by geometry modification concept. ASME District F-2013 Early Career Technical Conference, University of Alabama, 2-3 November 2013, Birmingham, Alabama, USA. 
[92] Ranjbar M, Marburg S, Hardtke HJ. Development of a hybrid neural networks algorithm for structural-acoustics optimization applications. In Proceedings of the First International Conference of Acoustics and Vibration, 21-22 December 2011, Tehran, Iran.

[93] Ranjbar M, Marburg S, Hardtke HJ. Schnelle optimierung in der struktur akustik. The 37annual meeting for Acoustics, 21-24 March 2011, Düsseldorf, Germany.

[94] Ranjbar M, Marburg S, Hardtke HJ. Ein vergleich von optimierungsverfahren fuer anwendungen in der strukturakustik. Proceedings of the 33-annual meeting for Acoustics, 19-22 March 2007, Stuttgart, Germany.

[95] Ranjbar M, Marburg S, Hardtke HJ. Study of optimization methods for structural-acoustic applications. Proceedings of 77th Annual Meeting of the Gesellschaft für Angewandte Mathematik und Mechanik e.V. 27-31 March 2006, Technische Universität Berlin, Germany.

[96] Chau K, Chan C, Liu C (2008) Overview of Permanent-Magnet Brushless Drives for Electric and Hybrid Electric Vehicles. IEEE transactions on industrial electronics 55(6): 2246-2257.

[97] Chan C, Chau K (2001) Modern electric vehicle technology. Oxford U.K: Oxford University Press.
[98] Parizet E, Janssens K, Martinez P, Pereira A, Lorencki J, Soriano J (2016) Sound quality of electric vehicles. NVH Analysis Techniques for Design and Optimization of Hybrid and Electric Vehicles, Aachen, Germany, Shaker Verlag GmbH, Germany 313-355.

[99] The Freedonia Group. World hybrid-electric vehicle. Cleveland, 2006.

[100] Parizet E (2014) Detectability and annoyance of warning sounds for electric vehicles. Proceedings of Meetings on Acoustics, Montreal.

[101] Parmar V, Rocco D, Hellinger V (2014) Noise and vibration effects of hybrid electric vehicles. Proceeding of ISMA, Graz, Austuria.

[102] Zhang Y, Lin H, Zhang B, Mi C (2004) Performance modeling and optimization of a novel multi-mode hybrid powertrain. Journal of Mechanical Design 128(1): 79-89.

[103] Lennström D, Lindbom T, Nykänen A (2013) Prominence of tones in electric vehicle interior noise. Noise Control for Quality of Life, Innesbruck, Austria.

[104] Parizet E, Bolmont A, Fingerhuth S (2009) Subjective evaluation of tonalness and relation between tonalness. Inter-Noise, Ottawa, Canada.

[105] Lennström D, Ågren A, Nykänen A (2011) Sound quality evaluation of electric carspreferences and influence of the test environment. Proceeding of Aachen Acoustic Colloquium, Aachen, Germany. 